\title{
Pyrexia in pregnancy: an atypical presentation
}

\section{Prasad Yeshwant Deshmukh*, Shaifali Kundan Patil, B. G. Boricha}

Department of Obstetrics \& Gynaecology, MGM Medical College, Navi Mumbai, Maharashtra, India

Received: 25 July 2014

Accepted: 8 August 2014

\author{
*Correspondence: \\ Dr. Prasad Yeshwant Deshmukh, \\ E-mail: drpydeshmukh@gmail.com
}

(C) 2014 Deshmukh PY et al. This is an open-access article distributed under the terms of the Creative Commons Attribution Non-Commercial License, which permits unrestricted non-commercial use, distribution, and reproduction in any medium, provided the original work is properly cited.

\begin{abstract}
Every year approximately 50 million women living in malaria endemic areas become pregnant and are at high risk of adverse health impact of malaria. Pregnancy appears to interfere with immune process in malaria and the disease itself alters immune reactivity. Malaria is a parasite infestation with protozoan Plasmodium; transmitted through bite of female Anopheline mosquito. We present a case of 25 week multigravida with vivax malaria complaining of breathlessness. On further investigations, patient was found to have bilateral pleural effusion.
\end{abstract}

Keywords: Malaria, Fever, Pregnancy, Plasmodium vivax, Breathlessness

\section{INTRODUCTION}

"Humanity has but three great enemies: fever, famine and war. Of these by far the greatest; by far the most terrible, is fever". Well said by William Osler a century ago.

As even today many antenatal women in developing countries are suffering of fever. Malaria is most important infection all over the world. It is indigenous in over 102 countries all over the world with 56 million population living in malaria endemic area. Ancient Indian Ayurveda gave vivid description of malaria and even associated its occurrence with mosquito bite. Approximately 2.5 million patients die of malaria with 56000 antenatal women losing their lives almost at par with antenatal HIV. ${ }^{1}$ It is caused by haemoparasite of genus Plasmodium with four species namely vivax, falciparum, malariae and ovale. ${ }^{2,3}$

\section{CASE REPORT}

A 22 year old gravida 2, para 1, living issue 1 patient 25 weeks period of gestation presented to our OPD with complaints of generalised weakness since 1 week, fever since 5 days, breathlessness since 3 days and vomiting 3 episodes. There was no h/o bleeding, leaking per vaginally, no h/o decreased foetal movements, no H/o burning micturition, no H/o cough, cold, sore throat. Her gestational age was 25 weeks by first trimester dating scan of $7.4 \mathrm{wks}$. She is registered for antenatal care and has received 1 dose of injection TT and currently taking iron-calcium tablets. She has a 5 years old female child full term normal vaginal delivery, delivered in hospital, immunised till date.

No H/o fever in recent past. No previous H/o blood transfusion. No H/o diabetes mellitus, hypertension, tuberculosis, bronchial asthma. Patient denies any addiction. Bowel Bladder habits are noted to be normal

On examination; her general condition was poor. Temperature $-102^{\circ} \mathrm{F}$ with pulse rate of $126 / \mathrm{min}$, respiratory rate $-40 / \mathrm{min}$, blood pressure $-90 / 60 \mathrm{mmHg}$ in right arm supine position and $\mathrm{SpO}_{2}-85 \%$ on pulse oximeter. On systemic examination, cardiovascular system was normal and respiratory system showed bilaterally reduced air entry. On obstetrical examination, uterus was 24-26 week gestational size, relaxed with variable presentation and foetal heart of 160/min regular. 
On investigation; haemoglobin - $6.4 \mathrm{gm} \%$, total count $4700 / \mathrm{mm}^{3}$, platelets - 43000/ $/ \mathrm{mm}^{3}$, blood group - B negative, HIV - negative, Australia antigen - negative, VDRL - negative, Urine R/M - within normal limits, RMA - positive for P. vivax, PS for MP - trophzoites of P. vivax G6PD - normal, dengue NS1 - non reactive, leptospira $\operatorname{IgM} / \operatorname{IgG}$ - non reactive, liver and kidney profile was normal, USG obstetrics - singleton intrauterine gestation of 25.3 weeks cephalic presentation with fundoanterior placenta, EFW $870 \mathrm{gm}$.

Pt was started on antimalarials in the form of inj. falcigo (120 mg) IV Stat followed by $(60 \mathrm{mg})$ IV every 6 hourly. 4 hourly RBS charting was done. 2 hourly foetal heart rate charting was maintained. Transfused 2 pints of packed RBCs. Serial monitoring for thrombocytopenia was done. Fever subsided after 2 doses of inj. falcigo. However despite this, breathlessness was not improving. Hence she was further investigated.
$\mathrm{X}$-ray chest - right sided lower segment collapse with $\mathrm{B} / \mathrm{L}$ mild to moderate pleural effusion (Chest X-ray done with abdominal shield).

USG chest - B/L pleural effusion approx. 20-30 cc fluid.

Tapping of pleural fluid was done. Fluid was pale yellow in colour, clear supernatant with absent coagulum. On microscopic examination RBCs $2700 / \mathrm{mm}^{3}$, WBCs $400 / \mathrm{mm}^{3}$ with normal protein levels.

Blood culture and sensitivity was done which had proven negative after 3 successive inoculations

Patient was put on 4 lit/ min $\mathrm{O}_{2}$ by mask. Intake / output charting was maintained. Inj. monocef (1 gm) IV BD for 5 days was given. Serial haemogram were done, as follows.

Table 1: Serial haemogram.

\begin{tabular}{|lllll|}
\hline & $16 / 09 / 2013$ & $18 / 09 / 2013$ & $20 / 09 / 2013$ & $24 / 09 / 2013$ \\
\hline $\mathrm{Hb}(\mathrm{gm} \%)$ & 6.4 & 7.4 & 8.6 & 9.0 \\
\hline TLC $\left(/ \mathrm{mm}^{3}\right)$ & 4700 & 6600 & 8400 & 8450 \\
\hline Platelets $\left(/ \mathrm{mm}^{3}\right)$ & 43000 & 71000 & 1.63 & 2.15 \\
\hline
\end{tabular}

The serial haemogram shows that after blood transfusion, the haemoglobin of pt has started rising dramatically, also platelet levels, which were very low initially, had started coming up significantly.

Patient was discharged on - Tab. lariago DS 1 tab. to be taken every Sunday till delivery as suppressive therapy. ${ }^{5}$ At present patient is on oral iron and calcium and following up every 2 weekly.

\section{DISCUSSION}

The malarial parasite has three to four different forms. Each form is specialised in living in a certain place.

The gametocyte is the form that infects the mosquito and reproduces itself, as if it were both sexes. When the mosquito has sucked blood containing gametocytes, these pass into the salivary glands of the mosquito, where they develop into a new form, the sporozoite. The infection can then move on. The sporozoite can be passed on to man when the mosquito bites, injecting its saliva into the tiny blood vessels. The sporozoite travels with the blood to the liver and enters the liver cells. In the liver some of the sporozoites divide (tachysporozoites) and become thousands of merozoites. The merozoites are released from the liver to the blood where they are taken up by the red blood corpuscles. Some of these turn into ring-formed trophozoites that split again to form schizonts. Schizonts burst the red blood corpuscles at a certain moment, releasing the merozoites. This release coincides with the violent rises in temperature during the attacks seen in many cases of malaria. The trophozoites that are left over during division can, in the course of the next day, develop into the sexual form, the gametocyte, which can be taken up by a blood-sucking mosquito and start another cycle. The incubation period (time from infection to development of the disease) is usually from 7 to 30 days (shorter periods with the deadliest form of falciparum). Plasmodium ovale and Plasmodium vivax can produce a dormant form, a hypnozoite, that can cause relapses of the disease months and even years after the original disease (relapsing malaria) because it's dormant in the liver cells. ${ }^{4}$

Malarial infection had been diagnosed by positive blood smear since antiquity. This pt presented to us with symptoms suggestive of malaria, however the complaint of breathlessness and $\mathrm{SpO}_{2}$ of $85 \%$ could not be explained by any aetiology. The diagnosis of pleural effusion became evident after chest X-ray and USG chest. Blood culture also proved the negative for microbial growth. Though there are records of pulmonary oedema occurring along with malaria, there is no study on record describing serositis or effusion presenting along with malaria in pregnancy.

Further, typical symptoms of malaria, anaemia, thrombocytopenia, detection of Plasmodium on peripheral smear all point the diagnosis of malaria. On starting anti-malarial medications, fever subsided. But breathlessness showed no improvement. 
Patient was directly started on inj. falcigo as the area where patient resides is known to be endemic for malaria.

We present this case to highlight the fact that malaria can present with variable clinical scenario. It is of paramount importance to investigate the patient meticulously, as pregnancy is an immunocompromised state and any trivial infection can take up stormy course during pregnancy. Further it is important to keep in mind incidence of congenital malaria. This is especially seen in patients coming from non-endemic areas, as in patients from endemic areas, passive transfer of $\mathrm{IgG}$ antibodies to foetus makes them immune during intrauterine life (incidence $0.3 \%$ ). Incidence of chorioamnionitis and subsequent preterm delivery also is seen much more commonly in cases of fever in pregnancy. ${ }^{6}$

Funding: No funding sources

Conflict of interest: None declared

Ethical approval: Not required

\section{REFERENCES}

1. Kumar A, Valecha N, Jain T, Dash AP. Ashwani Kumar, Neena Valecha. Burden of malaria in India: retrospective and prospective view. Am J Trop Med Hyg. 2007 Dec;77(6 Suppl):69-78.

2. Vidyadhar B. Bangal, Purushottam A. Giri. Study of pregnancy outcome in malaria among rural population of western Maharashtra, India. Int J Basic Appl Med Sci. 2012 May-Aug;2(2):108-11.

3. Neeru Singh, Mrigendra P. Singh. Malaria prevalence among pregnant women in two districts with differing endemicity in Chhattisgarh, India. Malaria J. 2012;11:274.

4. Marcus J. Rijken, Rose McGready. Malaria in pregnancy in the Asia-Pacific region. Lancet Infect Dis. 2012 Jan;12(1):75-88.

5. WHO. WHO policy brief for the implementation of intermittent preventive treatment of malaria in pregnancy using sulfadoxine-pyrimethamine (IPTpSP). In: WHO, eds. WHO Global Malaria Programme. Geneva: WHO; 2013: 1-12.

6. Catherine O. Falade, Olukemi O. Tongo. Effects of malaria in pregnancy on newborn anthropometry. $\mathrm{J}$ Infect Dev Ctries. 2010;4(7):448-53.

DOI: $10.5455 / 2320-1770$. ijrcog20140962

Cite this article as: Deshmukh PY, Patil SK, Boricha

BG. Pyrexia in pregnancy: an atypical presentation. Int J Reprod Contracept Obstet Gynecol 2014;3:836-8. 